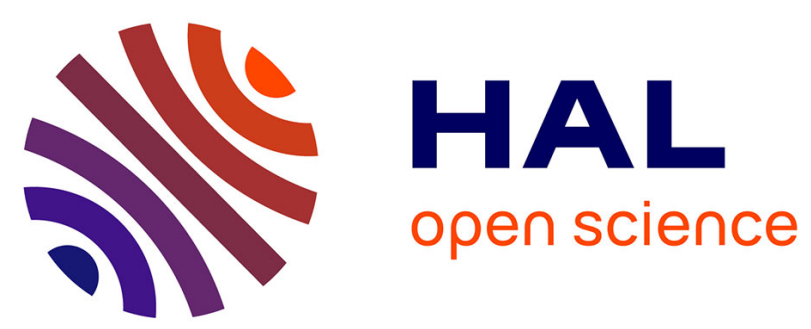

\title{
Hospitalization for adverse events under abiraterone or enzalutamide exposure in real-world setting: a French population-based study on prostate cancer patients
}

Lucie-Marie Scailteux, Fabien Despas, Frédéric Balusson, Boris

Campillo-Gimenez, Romain Mathieu, Sébastien Vincendeau, André Happe, Emmanuel Nowak, Sandrine Kerbrat, Emmanuel Oger

\section{To cite this version:}

Lucie-Marie Scailteux, Fabien Despas, Frédéric Balusson, Boris Campillo-Gimenez, Romain Mathieu, et al.. Hospitalization for adverse events under abiraterone or enzalutamide exposure in real-world setting: a French population-based study on prostate cancer patients. British Journal of Clinical Pharmacology, 2022, 88 (1), pp.336-346. 10.1111/bcp.14972 . hal-03281779

\author{
HAL Id: hal-03281779 \\ https://hal.science/hal-03281779
}

Submitted on 8 Sep 2021

HAL is a multi-disciplinary open access archive for the deposit and dissemination of scientific research documents, whether they are published or not. The documents may come from teaching and research institutions in France or abroad, or from public or private research centers.
L'archive ouverte pluridisciplinaire HAL, est destinée au dépôt et à la diffusion de documents scientifiques de niveau recherche, publiés ou non, émanant des établissements d'enseignement et de recherche français ou étrangers, des laboratoires publics ou privés. 
SCAILTEUX Lucie-Marie (Orcid ID: 0000-0001-7047-9107)

Oger Emmanuel (Orcid ID: 0000-0001-9837-2977)

Hospitalization for adverse events under abiraterone or enzalutamide exposure in realworld setting: a French population-based study on prostate cancer patients.

Running title: Real-world safety of abiraterone and enzalutamide.

Lucie-Marie SCAILTEUX ${ }^{1,2,3}$, Fabien DESPAS ${ }^{4,5}$, Frédéric BALUSSON², Boris CAMPILLO-

GIMENEZ ${ }^{6,7}$, Romain MATHIEU ${ }^{8,9}$, Sébastien VINCENDEAU ${ }^{8}$, André HAPPE ${ }^{2,3}$, Emmanuel NOWAK ${ }^{3,10}$, Sandrine KERBRAT ${ }^{2,3}$, Emmanuel OGER ${ }^{1,2,3}$.

1. Pharmacovigilance, Pharmacoepidemiology and Drug Information Centre, Department of Clinical Pharmacology, Rennes University Hospital, 35033 Rennes, France

2. Univ Rennes, EA 7449 REPERES 'Pharmacoepidemiology and Health Services Research', F 35000 Rennes, France

3. PEPS research consortium

4. Department of Clinical Pharmacology, Toulouse University Hospital, Toulouse, France

5. INSERM CIC 1436 Toulouse, Centre d'Investigation Clinique de Toulouse, Centre Hospitalier Universitaire de Toulouse, France

6. Eugène Marquis Comprehensive Cancer Regional Center, Rennes, France

7. Univ Rennes, INSERM 1099 'LTSI', F 35000 Rennes, France

8. Urology Department, Rennes University Hospital, Rennes, France

9. Univ Rennes, CHU Rennes, Inserm, EHESP, Irset (Institut de recherche en santé, environnement et travail) - UMR_S 1085, F-35000 Rennes, France

10. Université de Bretagne Loire, Université de Brest, INSERM CIC 1412, CHRU de Brest, France

Corresponding author: Lucie-Marie SCAILTEUX (ORCID iD: 0000-0001-7047-9107)

Luciemarie.scailteux@chu-rennes.fr

Pharmacovigilance Centre, Rennes University Hospital - 35000 Rennes - France

+33299284363

Key words: safety, adverse events, abiraterone, enzalutamide, castration-resistant prostate cancer, acute kidney injury, liver test monitoring.

This article has been accepted for publication and undergone full peer review but has not been through the copyediting, typesetting, pagination and proofreading process which may lead to differences between this version and the Version of Record. Please cite this article as doi: 10.1111/bcp.14972 
Word count: 3851

Figure count: 1

Table count: 3

\section{What is already known about this subject?}

- Safety profiles of abiraterone and enzalutamide still rely on phase-III clinical trials and several small cohorts, with missing information on rare and delayed adverse drug reactions.

- Using post-marketing data, pharmacovigilance and pharmaco-epidemiological studies are complementary approaches to complete drug safety profiles.

- A study of the French pharmacovigilance database highlighted safety signals that need to be further investigated by a pharmaco-epidemiological study: acute kidney injury and ischemic stroke with abiraterone; hepatotoxic risk, heart failure and atrial fibrillation with enzalutamide.

\section{What this study adds?}

- In a study on a 2013-2018 nationwide cohort of new French users of abiraterone and enzalutamide, we report incidence rates for specific adverse events leading to hospitalization in real-life setting, and we quantified incidence rate ratios for cardiac, renal, liver and neurological disorders.

- The incidence rates for adverse events that are known ADRs were partly in line with those provided in the summary of product characteristics for abiraterone and enzalutamide.

- Acute kidney injury, liver test monitoring suggestive of hepatic damage and atrial fibrillation were significantly more often observed in the abiraterone group than in the enzalutamide group. 


\section{Abstract (248/250 words)}

Aim. Safety profiles of abiraterone and enzalutamide mainly rely on phase III clinical trials. Our objective was to estimate the incidence rate ratio (IRR) for certain adverse events leading in real life to hospitalization (atrial fibrillation, acute heart failure, ischemic heart disease, acute kidney injury (AKI), ischemic stroke, torsade de pointe / QT interval prolongation, hepatitis, and seizure), comparing abiraterone to enzalutamide. We also set out to discuss previously identified safety signals.

Method. Using the French National Health Insurance System database, all patients newly exposed to abiraterone or enzalutamide between 2013 and 2017 and followed until December $31^{\text {st }}, 2018$ were targeted. IRR for each event were estimated using a Poisson model in a sub-population of patients without contraindications or precautions for use for either treatment.

Results. Among 11,534 new users of abiraterone and enzalutamide, AKI (IRR 1.42, 95\% Cl: 1.01-2.00), liver monitoring suggestive of hepatic damage (IRR 3.06, 95\% $\mathrm{Cl}: 2.66-3.53$ ), and atrial fibrillation (IRR 1.12, 95\% Cl: 1.05 -1.19) were significantly more often observed with abiraterone than with enzalutamide.

Conclusion. Our study provides knowledge on abiraterone and enzalutamide real-life safety profiles, especially for events leading to hospitalisation. Despite several limitations, including the lack of clinical data, the safety signal for AKI under abiraterone is in line with results of an analysis of the French pharmacovigilance database, which requires further specific investigations. Enlightening the clinicians' therapeutic choices for patients treated for prostate cancer, our study should lead to clinicians to be cautious in the use of abiraterone. 


\section{Introduction}

Abiraterone $\left(Z y t i g a{ }^{\circledR}\right.$, Janssen-Cilag International NV, Beerse, Belgium) and enzalutamide (Xtandi ${ }^{\circledR}$, Astellas Pharma Europe B.V., Leiden, The Netherlands) are two hormone therapies that have been available in France since June 2012 and February 2014 respectively in the treatment of metastatic castration-resistant prostate cancer (CRPCm). They have recently been recommended for non-metastatic CRPC and hormone-sensitive disease stages[1]. Regarding the safety profile of abiraterone, cardiac disorders are frequently observed and this motivates the implementation of routine risk minimization measures[2]. Hypertension, hypokalemia, fluid retention and cardiac failure are expected, due to an excess of mineralocorticoid induced by abiraterone resulting from CYP $17 \mathrm{~A} 1$ enzyme inhibition[3,4]; atrial fibrillation is also common[5]. Monitoring cardiac function is recommended, as well as caution in use among patients with a history of cardiovascular (CV) disease. Combination with corticosteroids is recommended to suppress the adrenocorticotropic hormone (ACTH) drive and to limit the occurrence and severity of these adverse drug reactions. Because of the frequent early increase in levels of liver enzymes and rare cases of fatal hepatitis, hepatotoxicity is an important identified risk related to abiraterone, which motivates an early, close follow-up of liver function [2]. The cause of hepatic damage is unknown but could be related to CYP 17A1 enzyme inhibition[6]; other mechanisms could exist in view of the cases described in the French pharmacovigilance database[7]. Regarding enzalutamide, neurological, cardiac and general disorders, especially headache, attention disorders, fatigue, ischemic heart disease, hypertension, falls or fractures, are all among the most expected adverse drug reactions[8,9]. Seizures are mentioned as an important, although uncommon, identified risk in the EMA risk management plan for Xtandi ${ }^{\circledR}[10]$. Potentially serious, QT interval prolongation is mentioned in the safety profiles of both drugs, but the frequency is not known $[5,11]$.

Data on safety profiles still relies on phase-III clinical trials [12-17] because subsequent cohort studies have included only small numbers of patients[18-23]. Post-marketing data, including rare and delayed ADRs observed in real life is required. Pharmacovigilance is crucial in identifying new drug safety signals, in assessing specific drug imputability, and in providing pharmacological hypotheses [24]. Assessment of drug imputability differs from the evaluation of risk and causality as carried out in population-based studies[25]. Because of several biases in spontaneous reporting[24], pharmacovigilance does not make it possible 
to determine the incidence of ADRs, nor can it estimate and quantify the risk of the suspected ADRs for a given drug, which is however possible in a pharmaco-epidemiological approach. These two approaches are indeed clearly complementary [26].

An analysis of the European pharmacovigilance database (Eudravigilance; www.adrreports.eu) targeting abiraterone and enzalutamide as suspect drugs from January 2013 to January 2019, suggested different adverse drug reaction profiles according to age from those identified in phase-III clinical trials. As expected, the analysis showed that several adverse drug reactions had not been reported in trials[27]. No precise descriptions of reactions were provided and no individual clinical descriptions were available on Eudravigilance, limiting in-depth analyses of the adverse drug reaction signals. As a first step in this population-based study, we performed an analysis of the French Pharmacovigilance database[7] which includes the spontaneous ADR cases reported by clinicians and patients between 2011 and 2017. This suggested that, although expected, the risk of sometimes fatal hepatotoxicity with abiraterone is difficult to anticipate, in spite of close follow-up of liver function. Excluding other potential aetiologies, safety signals for acute kidney injury (AKI) and ischemic stroke have emerged with abiraterone. The issue of hepatotoxic risk has also been raised with enzalutamide, and safety signals for heart failure and atrial fibrillation have emerged.

In the present study, we focused on the potentially serious adverse events, i.e. those that led to hospitalization. Choosing a deliberate "pharmacovigilance" orientation for our study, the objective here was 1 / to estimate the incidence rates for abiraterone and enzalutamide hospitalization-related adverse events (including safety signals) in real life, and 2 / to discuss previously identified safety signals. No data-mining analysis was performed.

\section{Methods}

Study design. The 'SPEAR' (Safety and Performance of Enzalutamide and Abiraterone) cohort was a 6-year nationwide study (2013-2018) based on a medico-administrative database.

Data sources. The pseudo-anonymous French National Health Insurance System was used (the SNDS database, covering about $99 \%$ of the French population; 67 million people). Linking a healthcare reimbursement database (DCIR) to the French hospital discharge database (PMSI), the SNDS database contains individual data on health expenditure 
reimbursements (biological and pathology investigations, consultations with clinicians, etc.), medication, vital status, details on medical acts as well as hospital discharge diagnoses (International Statistical Classification of Diseases, 10th [ICD-10] codes). The SNDS database does not include reasons for medical consultations, diagnoses for short stays in Emergency Departments, or clinical information: for instance, electrocardiogram results, liver tests or electroencephalograms are not available. It should be noted that, given the nature of the data sources and the impossibility of reliably linking events to drugs, and in accordance with pharmacovigilance methods, we have used the terminology of "adverse events" and not "adverse drug reactions."

Events of interest. Using the ICD-10 codes (except when stated otherwise; Appendix table S1), we identified patients hospitalised for the following reasons : 1) acute cardiac failure or decompensation, 2) ischemic stroke, 3) ischemic heart diseases, 4) atrial fibrillation, 5) convulsion/seizure, 6) AKI, 7) hepatitis, 8) torsade de pointe (TdP) and QT interval prolongation (a composite outcome that also included ventricular tachycardia); and finally 9) liver monitoring suggestive of hepatic damage by way of $\geq 4$ liver tests per month between the first and third month after drug initiation and/or $\geq 3$ liver tests per month after the third month of treatment, based on the fact that liver monitoring is recommended with abiraterone every two weeks for the first three months of treatment and monthly thereafter[5]).

Exposure and study population.

All patients who were exposed to abiraterone or enzalutamide from 2013 to 2017 were targeted using the Anatomical Therapeutic Chemical (ATC) codes in the healthcare reimbursement database (Appendix table S1). These prescriptions served as proxies for PCa progression towards the MCRPC stage. Patients with cancers other than PCa identified before the initiation of abiraterone or enzalutamide were excluded. The end of drug exposure was defined by the last abiraterone or enzalutamide reimbursement date followed by at least 30 days without abiraterone / enzalutamide issue, assuming that 30 days of follow-up were available. Patient follow-up was censored in case of a change in medication (abiraterone/enzalutamide and vice-versa or instatement of chemotherapy), in case of cessation of drug exposure, and in case of patient death or after December $31^{\text {st }}, 2018$, whichever came first. 
Two distinct cohorts of patients were formed. The overall population included all male adults who were new users of abiraterone or enzalutamide (no reimbursement identified in the 3 years preceding the first reimbursement. The date of the first reimbursement was considered as the starting date (TO) of follow-up. Two groups were established on the basis of the first drug received. In these populations, all patients who experienced an event under treatment were identified. The "sub-population" included patients without contraindications or precautions for use for either treatment $[5,11]$, i.e. patients without renal disease, mild to severe liver disease, myocardial infarction or the use of antiepileptic drugs, and who were new users of abiraterone and enzalutamide (two groups of patients based on the first treatment received) (Appendix Table S3).

\section{Analyses.}

In the overall population, each event was reported independently, without prioritization or censorship at the first event occurring. Using a Poisson model, the crude incidence rate per 100 person-years (PYs) was estimated with a $95 \%$ confidence interval $(95 \% \mathrm{Cl})$ for each event. If fifty or more occurrences were identified for any of the events, a descriptive subgroup analysis was performed, stratified according to the presence of risk factors and history of events of interest to distinguish between new events and event recurrence (Appendix table S2). For descriptive purposes, the incidence rates of the different events are presented per period of time, over the first two years of treatment. In the "sub-population", using standardized differences, a comparison of distributions of the baseline characteristics between groups was made. Incidence rates for abiraterone and enzalutamide events were compared by estimating the incidence rate ratios (IRR) for each event using a Poisson model without covariate adjustment. The choice of the reference drug was enzalutamide. In the sub-population, sensitivity analyses were conducted using a composite variable which focused on cardiovascular (CV) events liable to entail hospitalization or sudden cardiac death. Under a first definition, "CV morbidity", we identified patients with hospitalization for ischemic heart disease and torsade de pointe \& QT interval prolongation occurring between January $1^{\text {st }}, 2013$ and December 31 3 st 2018 . We then intended to take sudden cardiac death into account. In France, the cause of death is recorded on death certificates according to the ICD-10 codes and is included in a national database[28]. A law passed in 2016 allows the linkage of the cause of death database to the SNDS database[28] but at the time of the present study, only causes of deaths occurring between 2013 and 2016 were 
available on the SNDS database. Consequently, a time restriction was applied to our initial CV morbidity definition, identifying events between 2013 and 2016. Finally, in addition to the time restriction, patients who died between 2013 and 2016 in a CV context or from sudden cardiac death were added (Appendix table S1). The three incidence rate ratios were calculated using forest plots, with enzalutamide as the reference group.

Covariates. In order to identify potential risk factors, history of earlier events, and contraindications or precautions for use for either treatment, several chronic comorbidities were identified in the 3 years before T0 (Appendix table S1): chronic renal disease, hypertension, diabetes, atrial fibrillation, cardiac failure, cardiac valve disease, arterial ischemic disease (stroke, myocardial infarction and other coronary disorders), non-druginduced liver damage (HIV, liver disease, pancreatitis, alcohol use disorders), convulsive disorders and risk factors (Alzheimer's disease, ischemic or transient stroke, arteriovenous malformations of the brain, brain infection, traumatic brain injury, meningioma...), as well as variables included in the modified Charlson comorbidity index according to Bannay et al.[29]. Specific treatments were also identified (anti-diabetics, anticoagulants, platelet inhibitors, opiates, bisphosphonates, bone metastasis treatment, benzodiazepines, other medications that can modify the seizure threshold, antiepileptic drugs), as were prostatic specific antigen (PSA) titration and liver monitoring (alanine transaminase, aspartate aminotransferase, alkaline phosphatase).

All analyses were conducted using the SAS statistical package (version 9.4; SAS Institute, Cary, NC, USA).

Funding and ethical statement

The present study is part of the "PEPS" research program funded by the French Drug Agency "ANSM". The study protocol was authorized and approved by the ANSM on May 03, 2018. We used their permanent access to French health databases that is automatically granted to certain government agencies, public institutions and public service authorities, and did not require patient consent or ethics committee approval. 


\section{Results}

Between 2013 and 2017, 15,340 patients initiated hormone therapies: 10,647 (69.4 \%) were new users of abiraterone, and 4,693 (30.6 \%) new users of enzalutamide (Figure 1). The mean age was close between the two groups, 76.9 and 78.0 years respectively. Patient characteristics and risk factors for the different events are presented in Table 1. While around $77 \%$ of the overall cohort had liver monitoring in the 6 months before inclusion, $83 \%$ had liver monitoring in the 3 months following drug initiation (91\% among abiraterone users, 75\% among enzalutamide users). The mean follow-up time was 421.7 ( \pm 373.8 ) days for abiraterone users and 446.1 ( \pm 323.4 ) days for enzalutamide users. Nearly $51 \%$ of the patients $(n=7,776)$ had at least one event, among whom $78.2 \%$ had only one event, $19.7 \%$ had two, $2.0 \%$ had three, and the remainder four or five events. Details are presented in the Appendix table S4. Table 2 shows the numbers and incidence rates for each event, as well as the frequency categories in clinical trials according to the summaries of product characteristics; Appendix Table S5 shows the sub-group analyses, in particular for patients without a history of risk factors for a given event. The most frequently observed events with both drugs were atrial fibrillation, liver monitoring suggestive of hepatic damage, acute heart failure, and AKI. In contrast, hospitalization for ischemic stroke ( $n=129)$, TdP / QT interval prolongation $(n=26)$, hepatitis $(n=9)$, and seizure / convulsion $(n=5)$ had incidence rates of fewer than 10 cases per 1000 person-years in each treatment group. Of the 9 patients hospitalized for hepatitis (including acute hepatitis and fulminant hepatitis), 7 patients died, 2 within 2 days, and the others from one month to a few years after hospitalization. Regarding patients with liver monitoring suggestive of hepatic damage, none was hospitalized for hepatitis (Appendix Table S4). Irrespective of the type of event, incidence rates were higher during the first quarter of treatment, then decreased in the second quarter and stabilized over time (Appendix Figure S1).

The baseline characteristics of the sub-population of patients without contraindications or precautions for use for either treatment $(n=11,534)$ are presented in Appendix Table S6. Apart from the current use of medication potentially altering the seizure threshold, no crude differences were observed between groups. The IRR are presented in Table 3 (Appendix Table S7 for incidence rates): AKI (IRR 1.42, 95\% Cl: 1.01-2.00), liver monitoring suggestive of hepatic damage (IRR 3.06, 95\% Cl: 2.66 -3.53) and atrial fibrillation (1.12, 95\% $\mathrm{Cl}: 1.05-1.19)$ were significantly more often observed in the abiraterone group than in the 
enzalutamide group. Regarding sensitivity analyses, the incidence rate ratio of CV morbidity was close to 1.00 over the 2013-2018 period and around 0.70 in the period 2013-2016; the addition of sudden cardiac deaths did not change the estimate of the incidence rate ratio (Appendix Table S7 and Figure S2).

\section{Discussion}

Using the French National Health Data System for the period 2013 to 2018, we were able to provide new information on the safety profiles of abiraterone and enzalutamide, focusing on events leading to hospitalization: first, we were able to show real-life incidence rates, including rare and potentially delayed serious adverse events; second, the incidence rate ratios for several adverse events were quantified, including potentially new serious adverse events.

\section{Overall population incidence rates}

To our knowledge, we have provided for the first time the incidence rates for selected serious events, i.e. leading to hospitalization in a real-world setting. Regarding our first objective, the incidence rates for adverse events that are known ADRs were partly in line with those provided in the summary of product characteristics (SPC) of Zytiga ${ }^{\circledR}$ [5] or Xtandi ${ }^{\circledR}[11]$.

Several ICD-10 codes do not distinguish between incident and prevalent events (e.g. I50 / heart failure or 148 / atrial fibrillation), they require the use of more complex definitions with variable sensitivity and specificity values[30-32]. Using the classifications available in the SNDS (drugs, discharge diagnoses, medical acts), we chose to perform sub-groups analyses to get around this problem.

It should be noted that for atrial fibrillation, frequently expected with both drugs $[10,11]$ and identified in our study, it could be explained by the proportion of elderly patients, among whom $28 \%$ had a history of atrial fibrillation. Atrial fibrillation incidence increases with age and among men aged 74-79 compared to $\geq 80$ for CV disease, and can reach 45.6 and 76.1 per 1000 patient-years, respectively[30]. 


\section{Sub-population incidence rates ratios}

Regarding our second objective, on a sub-population of patients without heart failure, chronic renal disease, mild-to-severe liver disease, myocardial infarction or antiepileptic drug treatment, AKI, liver monitoring suggestive of hepatic damage, and atrial fibrillation were significantly more often observed with abiraterone than with enzalutamide. More precisely, for AKI, the sensitivity of ICD-10 codes for AKI (including acute dialysis) was low whilst specificity was high, which could have led to an under-estimation[33,34], but we thought this bias was not differential. AKI is not reported with abiraterone in the literature, with the exception of cases of rhabdomyolysis (uncommon with abiraterone[5]) where some patients had a history of renal disorders or were receiving rosuvastatin concomitantly[35-40]. Some authors suggest that abiraterone could increase plasma concentrations of rosuvastatin through the inhibition of OATP1B1, an efflux transporter[41], increasing statin muscular toxicity[40]. A French population-based study also suggested that the risk of AKI is moderately higher among men exposed to statins in primary prevention[42]. Dyslipidemia drugs were used for $35.7 \%$ of our sub-population without differences between groups, and they did not influence the AKI IRR estimation (data not shown). Cardiac or renal etiologies related to AKI were unlikely, as a history of heart failure and renal disease are criteria for non-inclusion in the sub-population. We found no data on the AKI related to the concomitant use of corticosteroids, which is recommended with abiraterone. It should be noted that the concomitant use of nephrotoxic treatments and the potential drug-drug interactions were not explored in depth.

Concerning the increase of prescriptions for liver monitoring, suggestive of hepatic damage, we are confident with this mode of estimation because patients with a history of liver disease were not included in the sub-population. The aminotransferase increase observed with abiraterone was expected since it is an important risk reported in the risk management plan for Zytiga ${ }^{\circledR}$ [2]; close liver monitoring is recommended early on, as a rise in aminotransferases is expected in the first quarter of treatment, which is consistent with our data. According to Livertox, enzalutamide is an unlikely cause of clinically apparent liver damage[43] and no liver monitoring is recommended with $\mathrm{Xtandi}^{\circledR}[11]$. A safety signal emerged for cholestatic hepatitis[7] and could not be excluded from our study in view of the incidence of liver monitoring suggestive of hepatic damage. Under-estimation of the liver monitoring variable is unlikely, since this monitoring requires clinician prescription and is 
reimbursed. No patient with suspected hepatic damage detected via liver monitoring was hospitalized for hepatitis in either group. However, we were unable to identify short-term treatment discontinuation or reintroduction at a reduced dosage, which could serve as a proxy for a transitory moderate-to-high rise in aminotransferases.

For atrial fibrillation, the increased IRR with abiraterone does not exclude a potential risk with enzalutamide, as a safety signal has already emerged[7].

\section{Other results}

Regarding ischemic stroke signal identified in the French pharmacovigilance study[7] with abiraterone, it is currently not confirmed, and, no IRR differences were observed between groups in the present study. A classification bias, although not differential, leading to a potential underestimation, could be present, even if some studies, including studies in France, have suggested good sensitivity and specificity values or positive predictive values on ICD-10 codes[44,45].

Regarding the hospitalisation for TdP \& QT interval prolongation, known with both drugs, whereas abiraterone is identified as a medication with a conditional risk of TdP, enzalutamide is not mentioned on the QT drug list [31]. TdP and QT interval prolongation, and to a lesser extent ischemic heart disease, are difficult to identify: as mentioned in previous observational studies[46-51], these events are infrequent, require electrocardiogram monitoring to establish a diagnosis and detailed case analyses to identify the drug-related events, and they can lead to sudden cardiac death. In our sensitivity analyses, no difference in CV morbidity +/- sudden cardiac death was observed between groups on the basis of the definitions used. However, we recognize the poor quality of recording of the cause of death (some coded as "cardio-respiratory arrest") since autopsies are the exception, and some causes of death, especially sudden cardiac death, are merely "presumed", and likely to be inaccurate[52].

Better knowledge of the safety profile of abiraterone and enzalutamide is required, since this conditions therapeutic choices. Other aspects concern costs and the impact on qualityof-life. Using data from phase-III clinical trials among patients with metastatic castrationresistant prostate cancer, the Functional Assessment of Cancer Therapy-Prostate and the Health-Related Quality of Life scores have been reported to be better with abiraterone or enzalutamide than with placebo[53]. A Danish randomized clinical trial exploring fatigue, 
health-related quality-of-life and metabolic adverse drug reactions among men with metastatic castration-resistant prostate cancer treated first-line with abiraterone and enzalutamide is currently recruiting patients (170 planned)[54]. However, short-term followup is a limitation for trials, meaning that they cannot provide information on delayed adverse drug reactions or quality of life over time.

\section{Strengths}

The analysis of reimbursement data provided an exhaustive exploration of patients who were issued the drugs of interest. The reimbursement data can enable detection of any significant change in treatment strategy, either via the initiation of drug treatments or via hospitalizations. The approach based on reimbursement data enables analysis in real-life conditions at population level.

To estimate the incidence rate ratios for each type of event (secondary objective), comparisons were performed on a cohort of patients who all presented the disease, i.e. metastatic castration-resistant cancer, and active comparators were chosen (first-line abiraterone or enzalutamide).

Our study focused on selected hospitalization-related adverse events as an indicator of potentially serious/life-threatening adverse events, which is relevant from a pharmacovigilance surveillance. Although we did not identify the full spectrum of events, we are confident that we identified all serious cases of adverse events without misclassification bias.

\section{Weaknesses}

In addition to the limitations discussed above for each type of event, we acknowledge the fact that no hierarchy was established across events. For instance, atrial fibrillation has a causal link with ischemic stroke, and is also related to heart failure[55,56].

We acknowledge that some events, such as stroke or myocardial infarction (if not rapidly fatal), were more likely to result in direct hospitalization. For other adverse events, only the most severe events potentially associated with complications were hospitalized (including fulminant hepatitis), with less severe stages (including most stages of liver toxicity) potentially managed by the outpatient practitioner or resulting in a short 
hospital/emergency room stay (in both cases, the diagnoses were not available on the SNDS database). But identifying less severe stages was not our ambition.

Due to missing clinical data in the SNDS database, it was not possible to provide information on the stage of the comorbidities and events. In addition, we were not able to determine the pathophysiological mechanism of some events (AKI, liver toxicity), which is essential to provide recommendations or precautions for use by clinicians.

Nor was it possible to reliably link adverse events to drug exposure; drug causality assessment is problematic, since events can be explained by other causes, including causes related to prostate cancer metastases.

We did not consider potential drug interactions in our study, and a specific analysis could provide additional knowledge to explain the occurrence of certain events (e.g. hepatotoxicity or nephrotoxicity).

Furthermore, interpretation of these results should be cautious, as type-I error cannot be excluded with several events.

\section{Conclusion}

Using the French National Health Insurance System SNDS, in a pharmacovigilance approach, we provided real-life incidence rates of $\mathrm{CV}$, neurological, hepatic and renal events leading to hospitalization among 15,340 new users of abiraterone and enzalutamide. The incidence rates for adverse events that are known ADRs were partly in line with those provided in the summary of product characteristics for abiraterone and enzalutamide. In a sub-population of patients without contraindications or precautions for use of either treatment, hospitalization for AKI was significantly more often observed in the abiraterone group than in the enzalutamide group. This observation should be considered as raising a new hypothesis that deserves further and more specific investigation. Close liver monitoring was significantly more often observed among abiraterone patients than among enzalutamide patients, but the risk of hepatotoxicity among the latter should not be excluded. Overall, given the discussed safety signals, our study provides elements that can enlighten the clinicians' therapeutic choices for patients treated for prostate cancer, and it should lead to clinicians to be cautious in the use of abiraterone. 


\section{Acknowledgments}

This publication represents the views of the authors and does not necessarily represent the opinion of the French Drugs Agency.

\section{Conflict of interest}

LMS, BCG, SK, FD, FB, AH, EN, EO: none.

Dr Vincendeau and Dr Mathieu report consulting or advisory roles for Astellas Pharma and Janssen-Cilag.

\section{Data sharing:}

The statistical code is available from the corresponding author. Under French law and regulations, patient-level data from SNDS cannot be made available.

The authors confirm that the Principal Investigator for this paper is Lucie-Marie SCAILTEUX, that she supervised all the project and has the responsibility for the integrity of the data and the accuracy of the data analysis.

\section{Author contributions}

Dr Scailteux, Pr Oger, Mrs Kerbrat had full access to all of the data that was used to generate the study population. The database extracted was stored in a dedicated space on the CNAMTS portal. Ms. Kerbrat carried out the data management (cleaning, table design and choice of variables for statistical analyses). They all take responsibility for the integrity of the data and the accuracy of the data analysis.

Conception and design: Scailteux, Oger.

Acquisition, analysis and interpretation of the data: All authors.

Drafting of the manuscript: Scailteux.

Critical revision of the manuscript for important intellectual content: All authors.

Statistical analysis: Kerbrat, Nowak, Scailteux, Oger.

Obtained funding: Scailteux, Oger.

Administrative, technical, or material support: Oger.

Supervision: Scailteux.

Critique of completed data analysis and interpretation in the manuscript: Campillo-Gimenez, Mathieu, Vincendeau. 


\section{References}

1. Teo MY, Rathkopf DE, Kantoff P. Treatment of Advanced Prostate Cancer. Annu Rev Med. 2019;70:479-499.

2. Zytiga ${ }^{\circledR}$-assessment-report-variation_Dec2017.pdf. Accessed July 22, 2020. https://www.ema.europa.eu/en/documents/variation-report/zytiga-h-c-2321-ii-0047-eparassessment-report-variation_en.pdf

3. Crawford ED, Higano CS, Shore ND, Hussain M, Petrylak DP. Treating Patients with Metastatic Castration Resistant Prostate Cancer: A Comprehensive Review of Available Therapies. J Urol. 2015;194(6):1537-1547.

4. Scott LJ. Abiraterone Acetate: A Review in Metastatic Castration-Resistant Prostrate Cancer. Drugs. 2017;77(14):1565-1576.

5. Zytiga®-epar-product-information_July2020.pdf. Accessed July 27, 2020. https://www.ema.europa.eu/en/documents/product-information/zytiga-epar-productinformation_en.pdf

6. Abiraterone. In: LiverTox: Clinical and Research Information on Drug-Induced Liver Injury. National Institute of Diabetes and Digestive and Kidney Diseases; 2017. Accessed November 13, 2020. http://www.ncbi.nlm.nih.gov/books/NBK548136/

7. Scailteux L-M, Lacroix C, Bergeron S, et al. Adverse drug reactions profiles for abiraterone and enzalutamide: A pharmacovigilance descriptive analysis. Therapies.

Published online 13 December 2020. doi:10.1016/j.therap.2020.12.012

8. Scott LJ. Enzalutamide: A Review in Castration-Resistant Prostate Cancer. Drugs. 2018;78(18):1913-1924. doi:10.1007/s40265-018-1029-9

9. Sternberg CN. Enzalutamide, an oral androgen receptor inhibitor for treatment of castration-resistant prostate cancer. Future Oncol. 2019;15(13):1437-1457.

10. Xtandi ${ }^{\circledR}$-epar-risk-management-plan-summary_January2019.pdf. Accessed July 22, 2020. https://www.ema.europa.eu/en/documents/rmp-summary/xtandi-epar-riskmanagement-plan-summary_en.pdf

11. Xtandi®-epar-product-information_March2020pdf. Accessed July 27, 2020. https://www.ema.europa.eu/en/documents/product-information/xtandi-epar-productinformation_en.pdf

12. Castellan P, Castellucci R, Marchioni M, et al. A drug safety evaluation of abiraterone acetate in the treatment of prostate cancer. Expert Opin Drug Saf. 2019;18(9):759-767.

13. Boukovala M, Spetsieris N, Efstathiou E. Systemic Treatment of Prostate Cancer in Elderly Patients: Current Role and Safety Considerations of Androgen-Targeting Strategies. Drugs Aging. 2019;36(8):701-717.

14. Roviello G, Sigala S, Sandhu S, et al. Role of the novel generation of androgen receptor pathway targeted agents in the management of castration-resistant prostate cancer: A literature based meta-analysis of randomized trials. Eur J Cancer. 2016;61:111-121.

15. Roviello G, Sigala S, Danesi R, et al. Incidence and relative risk of adverse events of special interest in patients with castration resistant prostate cancer treated with CYP-17 inhibitors: A meta-analysis of published trials. Crit Rev Oncol Hematol. 2016;101:12-20. 16. Moreira RB, Debiasi M, Francini E, et al. Differential side effects profile in patients with mCRPC treated with abiraterone or enzalutamide: a meta-analysis of randomized controlled trials. Oncotarget. 2017;8(48):84572-84578.

17. Zhu J, Liao R, Su C, et al. Toxicity profile characteristics of novel androgendeprivation therapy agents in patients with prostate cancer: a meta-analysis. Expert Rev Anticancer Ther. 2018;18(2):193-198.

18. Poon DMC, Chan K, Lee SH, et al. Abiraterone acetate in metastatic castrationresistant prostate cancer - the unanticipated real-world clinical experience. BMC Urol. 
2016;16:12.

19. Miyake H, Hara T, Terakawa T, Ozono S, Fujisawa M. Comparative Assessment of Clinical Outcomes Between Abiraterone Acetate and Enzalutamide in Patients With Docetaxel-Naive Metastatic Castration-Resistant Prostate Cancer: Experience in Real-World Clinical Practice in Japan. Clin Genitourin Cancer. 2017;15(2):313-319.

20. Poon DMC, Wong KCW, Chan TW, et al. Survival Outcomes, Prostate-specific Antigen Response, and Tolerance in First and Later Lines of Enzalutamide Treatment for Metastatic Castration-resistant Prostate Cancer: A Real-World Experience in Hong Kong. Clin Genitourin Cancer. 2018;16(5):402-412.e1. doi:10.1016/j.clgc.2018.07.008

21. Marret G, Doucet L, Hennequin C, Fizazi K, Culine S. Abiraterone in metastatic castration-resistant prostate cancer: Efficacy and safety in unselected patients. Cancer Treatment and Research Communications. 2018;17:37-42.

22. Koninckx M, Marco JL, Pérez I, Faus MT, Alcolea V, Gómez F. Effectiveness, safety and cost of abiraterone acetate in patients with metastatic castration-resistant prostate cancer: a real-world data analysis. Clin Transl Oncol. 2019;21(3):314-323.

23. Beardo P, Osman I, San José B, et al. Safety and outcomes of new generation hormone-therapy in elderly chemotherapy-naive metastatic castration-resistant prostate cancer patients in the real world. Arch Gerontol Geriatr. 2019;82:179-185.

24. Moore N, Berdaï D, Blin P, Droz C. Pharmacovigilance - The next chapter. Therapie. 2019;74(6):557-567.

25. Miremont-Salamé G, Théophile H, Haramburu F, Bégaud B. Causality assessment in pharmacovigilance: The French method and its successive updates. Therapie. 2016;71(2):179-186.

26. Soeiro T, Lacroix C, Micallef J. Adverse drug reaction monitoring: Doing it the French way - Act II. Therapie. Published online 6 November 2020.

doi:10.1016/j.therap.2020.11.002

27. De Nunzio C, Lombardo R, Tema G, et al. Adverse events related to abiraterone and enzalutamide treatment: analysis of the EudraVigilance database and meta-analysis of registrational phase III studies. Prostate Cancer Prostatic Dis. 2020;23(2):199-206. doi:10.1038/s41391-019-0182-x

28. Rey G, Bounebache K, Rondet C. Causes of deaths data, linkages and big data perspectives. Journal of Forensic and Legal Medicine. 2018;57:37-40.

29. Bannay A, Chaignot C, Blotière P-O, et al. The Best Use of the Charlson Comorbidity Index With Electronic Health Care Database to Predict Mortality. Med Care. 2016;54(2):188194.

30. Bosco-Lévy P, Duret S, Picard F, et al. Diagnostic accuracy of the International Classification of Diseases, Tenth Revision, codes of heart failure in an administrative database. Pharmacoepidemiology and Drug Safety. 2019;28(2):194-200.

31. Yao RJR, Andrade JG, Deyell MW, Jackson H, McAlister FA, Hawkins NM. Sensitivity, specificity, positive and negative predictive values of identifying atrial fibrillation using administrative data: a systematic review and meta-analysis. Clin Epidemiol. 2019;11:753-767.

32. Xu Y, Lee S, Martin E, et al. Enhancing ICD-Code-Based Case Definition for Heart Failure Using Electronic Medical Record Data. J Card Fail. 2020;26(7):610-617.

33. Vlasschaert MEO, Bejaimal SAD, Hackam DG, et al. Validity of Administrative Database Coding for Kidney Disease: A Systematic Review. American Journal of Kidney Diseases. 2011;57(1):29-43.

34. Hwang YJ, Shariff SZ, Gandhi S, et al. Validity of the International Classification of Diseases, Tenth Revision code for acute kidney injury in elderly patients at presentation to the emergency department and at hospital admission. BMJ Open. 2012;2(6):e001821. 
35. Neyra JA, Rocha NA, Bhargava R, Vaidya OU, Hendricks AR, Rodan AR.

Rhabdomyolysis-induced acute kidney injury in a cancer patient exposed to denosumab and abiraterone: a case report. BMC Nephrol. 2015;16:118.

36. Moore DC, Moore A. Abiraterone-induced rhabdomyolysis: A case report. J Oncol Pharm Pract. 2017;23(2):148-151.

37. Dineen M, Hansen E, Guancial E, Sievert L, Sahasrabudhe D. Abiraterone-induced rhabdomyolysis resulting in acute kidney injury: A case report and review of the literature. $J$ Oncol Pharm Pract. 2018;24(4):314-318.

38. Moore DC, Ringley JT. Rhabdomyolysis With Abiraterone Exposure: A Brief Review of the Food and Drug Administration Adverse Event Reporting System (FAERS). Ann

Pharmacother. 2018;52(11):1160-1161.

39. Ghafouri S, Drakaki A. Abiraterone-Induced Rhabdomyolysis in Prostate Cancer: A Report of Two Cases and Review of the Literature. Annals of Clinical Case Reports. 2018;3:1533.

40. Ould-Nana I, Cillis M, Gizzi M, Gillion V, Hantson P, Gérard L. Rhabdomyolysis and acute kidney injury induced by the association of rosuvastatin and abiraterone: A case report and review of the literature. J Oncol Pharm Pract. Published online 12 May 2020:107815522092300.

41. Benoist GE, Hendriks RJ, Mulders PFA, et al. Pharmacokinetic Aspects of the Two Novel Oral Drugs Used for Metastatic Castration-Resistant Prostate Cancer: Abiraterone Acetate and Enzalutamide. Clin Pharmacokinet. 2016;55(11):1369-1380.

42. Coste J, Karras A, Rudnichi A, et al. Statins for primary prevention of cardiovascular disease and the risk of acute kidney injury. Pharmacoepidemiol Drug Saf. 2019;28(12):15831590 .

43. Enzalutamide. In: LiverTox: Clinical and Research Information on Drug-Induced Liver Injury. National Institute of Diabetes and Digestive and Kidney Diseases; 2017. Accessed December 15, 2020. http://www.ncbi.nlm.nih.gov/books/NBK548070/ 44. Giroud M, Hommel M, Benzenine E, et al. Positive Predictive Value of French Hospitalization Discharge Codes for Stroke and Transient Ischemic Attack. ENE. 2015;74(12):92-99.

45. Hall R, Mondor L, Porter J, Fang J, Kapral MK. Accuracy of Administrative Data for the Coding of Acute Stroke and TIAs. Canadian Journal of Neurological Sciences. 2016;43(6):765-773.

46. Darpö B. Spectrum of drugs prolonging QT interval and the incidence of torsades de pointes. Eur Heart J Suppl. 2001;3(suppl_K):K70-K80.

47. Molokhia M, Pathak A, Lapeyre-Mestre M, et al. Case ascertainment and estimated incidence of drug-induced long-QT syndrome: study in Southwest France. Br J Clin Pharmacol. 2008;66(3):386-395.

48. Robitaille C, Bancej C, Dai S, et al. Surveillance of ischemic heart disease should include physician billing claims: population-based evidence from administrative health data across seven Canadian provinces. BMC Cardiovasc Disord. 2013;13:88.

49. McCormick N, Lacaille D, Bhole V, Avina-Zubieta JA. Validity of myocardial infarction diagnoses in administrative databases: a systematic review. PLoS One. 2014;9(3):e92286.

50. Huang Y, Alsabbagh MW. Estimates of population-based incidence of malignant arrhythmias associated with medication use-a narrative review. Fundam Clin Pharmacol. 2020;34(4):418-432.

51. Danielsson B, Collin J, Nyman A, et al. Drug use and torsades de pointes cardiac arrhythmias in Sweden: a nationwide register-based cohort study. BMJ Open.

2020;10(3):e034560. 
52. Tseng ZH, Olgin JE, Vittinghoff E, et al. Prospective Countywide Surveillance and Autopsy Characterization of Sudden Cardiac Death: POST SCD Study. Circulation. 2018;137(25):2689-2700. doi:10.1161/CIRCULATIONAHA.117.033427

53. Kretschmer A, Ploussard G, Heidegger I, et al. Health-related Quality of Life in Patients with Advanced Prostate Cancer: A Systematic Review. Eur Urol Focus. Published online 20 February 2020. doi:10.1016/j.euf.2020.01.017

54. Kvorning Ternov K, Sønksen J, Fode M, et al. Fatigue, quality of life and metabolic changes in men treated with first-line enzalutamide versus abiraterone plus prednisolone for metastatic castration-resistant prostate cancer (HEAT): a randomised trial protocol. $B M J$ Open. 2019;9(9). Accessed December 15, 2020.

https://www.ncbi.nlm.nih.gov/pmc/articles/PMC6747677/

55. Anter Elad, Jessup Mariell, Callans David J. Atrial Fibrillation and Heart Failure. Circulation. 2009;119(18):2516-2525.

56. Kamel H, Okin PM, Elkind MSV, Iadecola C. Atrial Fibrillation and Mechanisms of Stroke: Time for a New Model. Stroke; a journal of cerebral circulation. 2016;47(3):895. 
Table 1. Baseline characteristics of the overall population according to the first line castration-resistant prostate cancer treatment $(n=15340)$

\begin{tabular}{|c|c|c|c|c|c|c|}
\hline & \multicolumn{2}{|l|}{ Overall } & \multicolumn{2}{|c|}{ Abiraterone } & \multicolumn{2}{|c|}{ Enzalutamide } \\
\hline & $\mathrm{n}$ & $\%$ & $\mathrm{n}$ & $\%$ & $\mathrm{n}$ & $\%$ \\
\hline & 15340 & 100 & 10647 & 69,4 & 4693 & 30,6 \\
\hline Mean age (sd) & & & $76.9(9.0)$ & & $78.0(9.2)$ & \\
\hline $\begin{array}{l}\text { Naïve to chemotherapy used for prostate } \\
\text { cancer }\end{array}$ & 13743 & 89.6 & 9454 & 88.8 & 4289 & 91.4 \\
\hline \multicolumn{7}{|l|}{ Cardiovascular risk factors } \\
\hline Hypertension & 9794 & 63.8 & 6774 & 63.6 & 3020 & 64.4 \\
\hline $\begin{array}{l}\text { Recent use of drugs licensed for } \\
\text { hypertension or cardiac failure }\end{array}$ & 10709 & 69.8 & 7350 & 69.0 & 3359 & 71.6 \\
\hline Diabetes (with or without organ damage) & 3062 & 20 & 1998 & 18.8 & 1064 & 22.7 \\
\hline Recent use of dyslipidemia drugs & 6581 & 42.9 & 4492 & 42.2 & 2089 & 44.5 \\
\hline $\begin{array}{l}\text { Smoking or chronic obstructive } \\
\text { pneumopathy disorders }\end{array}$ & 1433 & 9.3 & 936 & 8.8 & 497 & 10.6 \\
\hline Obesity & 837 & 5.5 & 514 & 4.8 & 323 & 6.9 \\
\hline \multicolumn{7}{|l|}{ Cardiovascular diseases } \\
\hline Atrial fibrillation & 4307 & 28.1 & 2879 & 27.0 & 1428 & 30.4 \\
\hline $\begin{array}{l}\text { Heart diseases (heart failure including } \\
\text { cardiomyopathy) }\end{array}$ & 1128 & 7.4 & 735 & 6.9 & 393 & 8.4 \\
\hline $\begin{array}{l}\text { Torsade de pointe or congenital long QT } \\
\text { syndrome }\end{array}$ & 0 & 0.0 & 0 & 0.0 & 0 & 0.0 \\
\hline Cardiac valve disorders & 486 & 3.2 & 301 & 2.8 & 185 & 3.9 \\
\hline Ischemic stroke & 276 & 1.8 & 184 & 1.7 & 92 & 2.0 \\
\hline Atherosclerosis and peripheral embolism & 432 & 2.8 & 275 & 2.6 & 157 & 3.3 \\
\hline $\begin{array}{l}\text { Ischemic heart disease and/or coronary } \\
\text { revascularisation }\end{array}$ & 2420 & 15.8 & 1559 & 14.6 & 861 & 18.3 \\
\hline Carotid and peripheral angioplasty & 118 & 0.8 & 72 & 0.7 & 46 & 1.0 \\
\hline Recent use of anticoagulants\$ & 2170 & 14.1 & 1449 & 13.6 & 721 & 15.4 \\
\hline Recent use of antiplatelet inhibitors $\$$ & 5007 & 32.6 & 3366 & 31.6 & 1641 & 35.0 \\
\hline Chronic renal disease & 678 & 4.4 & 424 & 4.0 & 254 & 5.4 \\
\hline \multicolumn{7}{|l|}{ Non-drug induced liver damage: } \\
\hline Liver disease & 258 & 1.7 & 156 & 1.5 & 102 & 2.2 \\
\hline Pancreatitis & 15 & 0.1 & 11 & 0.1 & 4 & 0.1 \\
\hline HIV infection & 24 & 0.2 & 20 & 0.2 & 4 & 0.1 \\
\hline Alcohol use disorders & 266 & 1.7 & 183 & 1.7 & 83 & 1.8 \\
\hline \multicolumn{7}{|l|}{ Factors modifying seizure risk } \\
\hline Convulsive disorders & 86 & 0.6 & 60 & 0.6 & 26 & 0.6 \\
\hline Curent use of benzodiazepine & 3283 & 21.4 & 2331 & 21.9 & 952 & 20.3 \\
\hline $\begin{array}{l}\text { Curent use of medication that can } \\
\text { modify seizure threshold }\end{array}$ & 6385 & 41.6 & 4597 & 43.2 & 1788 & 38.1 \\
\hline $\begin{array}{l}\text { Recent use of antiepilectic drugs or } \\
\text { chronic/ neuropathic pain drugs }\end{array}$ & 3 & 0.0 & 2 & 0.0 & 1 & 0.0 \\
\hline $\begin{array}{l}\text { Other seizure risk factors and brain } \\
\text { disorders }{ }^{f}\end{array}$ & 0 & 0.0 & 0 & 0.0 & 0 & 0.0 \\
\hline
\end{tabular}

$\$$ these variables are considered as proxy of cardiovascular diseases.

$\mathrm{f}$ including traumatic brain or head injury within the last 12 months, arteriovenous malformations of the brain, brain infection (i.e. abscess, meningitis, or encephalitis), Alzheimer's disease, meningioma. 
Table 2. Number of events and crude incidence rates in the overall population $(n=15340)$

\begin{tabular}{|c|c|c|c|c|c|c|c|c|c|}
\hline Outcome & $\begin{array}{c}\text { Overall } \\
\text { population } \\
n=15340 \\
n\end{array}$ & $\mathrm{n}$ & person-year & $\begin{array}{l}\text { raterone } \\
=10647 \\
\text { Incidence per } 1000 \\
\text { person-years } \\
\text { (confidence interval 95\%) }\end{array}$ & $\begin{array}{l}\text { Frequency categories in } \\
\text { clinical trials }\end{array}$ & $\mathrm{n}$ & person-year & $\begin{array}{l}\text { lutamide } \\
=4693 \\
\text { Incidence per } 1000 \\
\text { person-years } \\
\text { (confidence interval 95\%) }\end{array}$ & $\begin{array}{l}\text { Frequency categories in } \\
\text { clinical trials }\end{array}$ \\
\hline Atrial fibrillation & 6549 & 4533 & 8763.2 & $517.3(502.4-532.6)$ & Common & 2016 & 4134.53 & $487.6(466.8-509.3)$ & $\begin{array}{c}\text { Not reported } \\
\text { but safety signal* }\end{array}$ \\
\hline Acute heart failure & 403 & 286 & 12167.1 & $23.5(20.9-26.4)$ & Common & 117 & 5674.25 & $20.6(17.2-24.7)$ & $\begin{array}{c}\text { Not reported } \\
\text { but safety signal* }\end{array}$ \\
\hline Ischemic stroke & 129 & 91 & 12244.4 & $7.4(6.1-9.1)$ & $\begin{array}{c}\text { Not reported } \\
\text { but safety signal* }\end{array}$ & 38 & 5708.8 & $6.7(4.8-9.2)$ & Not reported \\
\hline Ichemic heart disease & 197 & 125 & 12196.8 & $10.3(8.6-12.2)$ & Not known & 72 & 5684.7 & $12.7(10.1-16.0)$ & Common \\
\hline $\begin{array}{l}\text { Torsade de pointe, QT } \\
\text { interval prolongation }\end{array}$ & 26 & 17 & 12297.1 & $1.4(0.9-2.2)$ & Not known & 9 & 5732.12 & $1.6(0.8-3.0)$ & Not known \\
\hline $\begin{array}{c}\text { Close liver monitoring } \\
\text { suggestive of hepatic damage }\end{array}$ & 2020 & 1724 & 9887.7 & $174.4(166.3-182.8)$ & Very common & 296 & 5323.9 & $55.6(49.6-62.3)$ & Not reported \\
\hline Hepatitis & 9 & 8 & 12299.9 & $0.7(0.3-1.3)$ & $\begin{array}{c}\text { 'Acute hepatic failure, } \\
\text { fulminant hepatitis' } \\
\text { Rare }\end{array}$ & 1 & 5735.7 & $0.2(0.02-1.2)$ & $\begin{array}{c}\text { Not reported } \\
\text { but safety signal* }\end{array}$ \\
\hline Acute kidney injury & 312 & 237 & 12194.6 & $19.4(17.1-22.1)$ & $\begin{array}{c}\text { Not reported } \\
\text { but safety signal* }\end{array}$ & 75 & 5699.4 & $13.2(10.50-16.5)$ & Not reported \\
\hline Seizure / convulsion & 5 & 2 & 12299.6 & $0.2(0.04-0.7)$ & Not reported & 3 & 5731.8 & $0.5(0.2-1.6)$ & Uncommon \\
\hline
\end{tabular}

F Frequency categories are defined as follows: very common ( $\geq 1 / 10)$; common $(\geq 1 / 100$ to $<1 / 10)$; uncommon $(\geq 1 / 1,000$ to $<1 / 100)$; rare $(\geq 1 / 10,000$ to $<1 / 1,000)$; very rare $(<1 / 10,000)$; not known (cannot be estimated from the available trials data).

${ }^{*}$ Considered as safety signals from Scailteux et al. Adverse drug reactions profiles for abiraterone and enzalutamide: A pharmacovigilance descriptive analysis. Therapie. 2020. 
Table 3. Poisson estimated incidence rate ratios of the different events in the sub-population of patients without contraindications or precautions for use to either treatment $(n=11534)$.

\begin{tabular}{|c|c|c|c|c|c|c|c|c|c|}
\hline & \multicolumn{9}{|c|}{ Incidence rate ratio of each outcome (confidence interval 95\%) } \\
\hline Exposure & Atrial fibrillation & $\begin{array}{l}\text { Acute heart } \\
\text { failure }\end{array}$ & Ischemic stroke & $\begin{array}{l}\text { Ischemic heart } \\
\text { disease }\end{array}$ & $\begin{array}{c}\text { Torsade de } \\
\text { pointe, QT } \\
\text { interval } \\
\text { prolongation }\end{array}$ & Hepatitis & $\begin{array}{l}\text { Close liver } \\
\text { monitoring }\end{array}$ & $\begin{array}{c}\text { Acute kidney } \\
\text { injury }\end{array}$ & $\begin{array}{l}\text { Seizure / } \\
\text { convulsion }\end{array}$ \\
\hline Abiraterone & $1.12(1.05-1.19)$ & $1.34(0.99-1.82)$ & $1.23(0.78-1.94)$ & $0.99(0.65-1.5)$ & $0.79(0.26-2.35)$ & $3.06(0.38-24.91)$ & $3.06(2.66-3.53)$ & $1.42(1.01-2.00)$ & $0.44(0.06-3.11)$ \\
\hline
\end{tabular}




\section{Figure 1.}

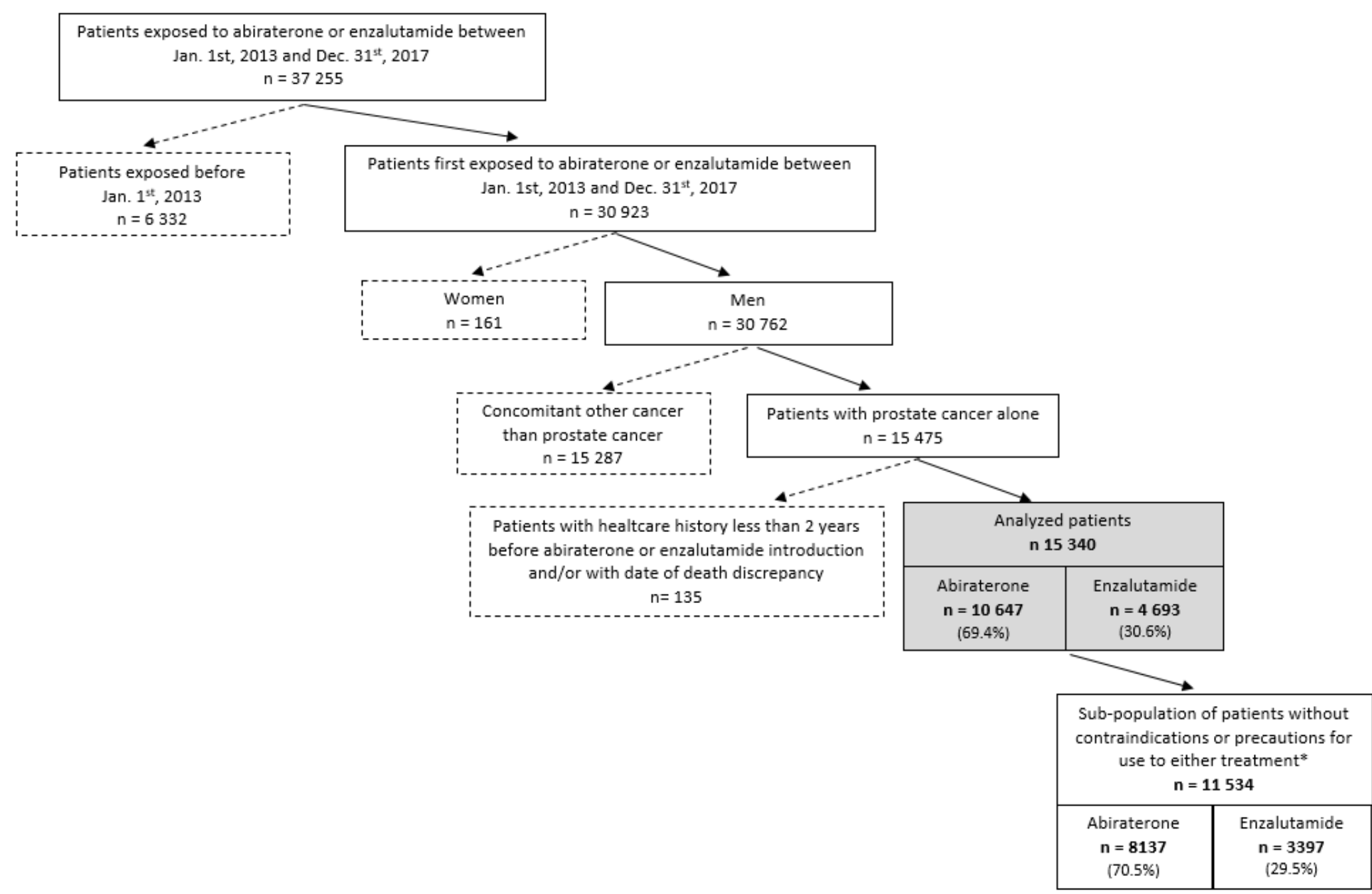

*Contraindications or precaution for use concerned history in the 3 previous years of abiraterone or enzalumide start of heart failure, chronic renal disease, moderate or severe liver disease, QT interval prolongation, seizure/convulsions and in the year prior to the drug start, myocardial infarction and the use of antiepileptic drugs. 


\section{Hospitalization for adverse events under abiraterone or enzalutamide exposure in real-world setting}

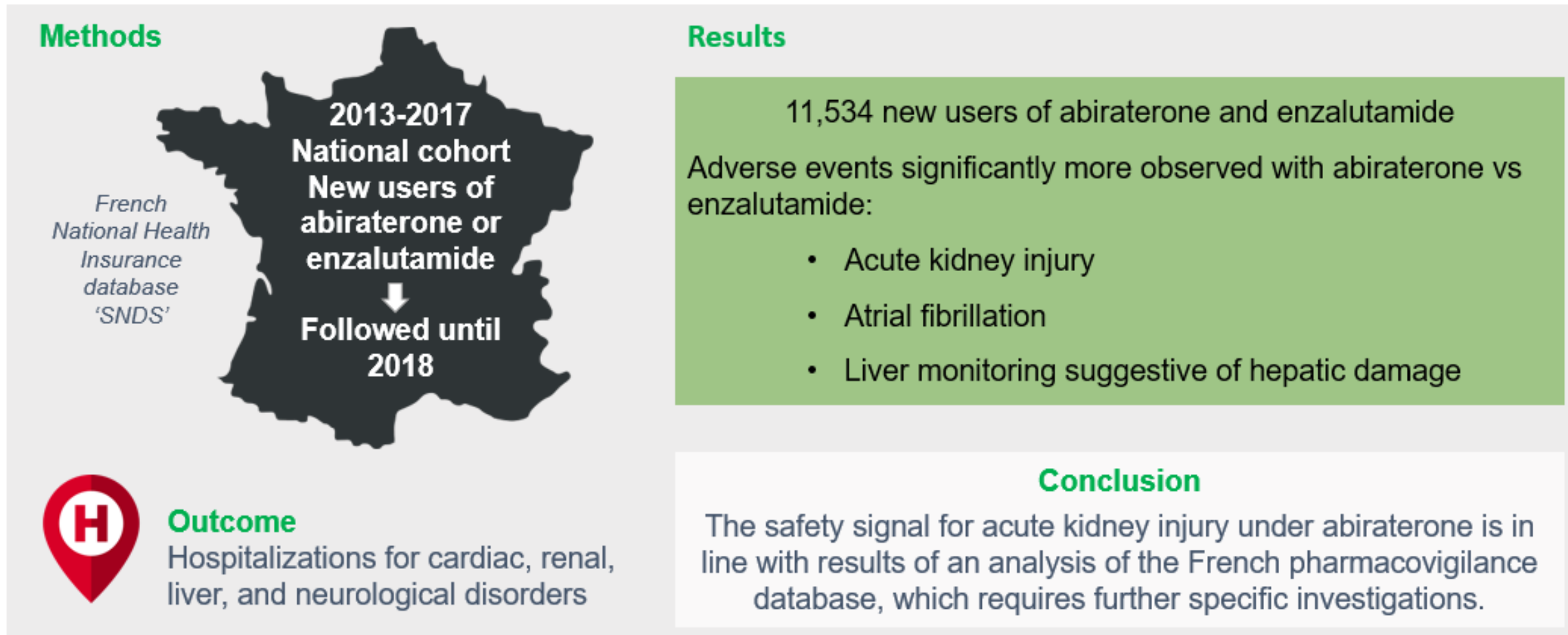

Scailteux L-M, et al. Br. J. Clin. Pharmacol. 2021 